\title{
The good, the bad and the ugly: Emys trinacris, Placobdella costata and Haemogregarina stepanowi in Sicily (Testudines, Annelida and Apicomplexa)
}

\author{
Vincenzo Arizza ${ }^{1}$, Francesco Sacco ${ }^{1}$, Debora Russo ${ }^{1}$, Rita Scardino ${ }^{1}$, Marco Arculeo ${ }^{1}$, Melita Vamberger $^{2}$ and $^{-}$ \\ Federico Marrone ${ }^{1}$ \\ ${ }^{1}$ Dipartimento di Scienze e Tecnologie Biologiche, Chimiche e Farmaceutiche, Sezione di Biologia Animale ed Antropologia \\ Biologica, Università degli Studi di Palermo, Palermo, Italy; \\ ${ }^{2}$ Museum für Tierkunde, Senckenberg Dresden, Dresden, Germany
}

\begin{abstract}
Endemic Sicilian pond turtles Emys trinacris Fritz, Fattizzo, Guicking, Tripepi, Pennisi, Lenk, Joger et Wink were examined for the presence of haemogregarine parasites. The presence of haemogregarines, occurring mainly in the microgametocyte stage $(13.2 \pm 0.12 \mu \mathrm{m}$ in length and $6.4 \pm 0.52 \mu \mathrm{m}$ in width), was observed in approximately $9 \%$ of the sampled E. trinacris. Based on the observed morphology and on the sequencing of nuclear 18S rDNA, we identified the parasite as Haemogregarina stepanowi Danilewsky, 1885. Morphometric study of uninfected and infected red blood cells has shown that $H$. stepanowi induces different changes in erythrocyte shape depending on the infective stage. The differential count of leukocytes in specimens infected with $H$. stepanowi showed no significant difference compared with healthy specimens. However, considering the health problems which might be induced by H. stepanowi in the closely related European pond turtle Emys orbicularis (Linneaus), monitoring of the health status of the infected Sicilian populations of E. trinacris is desirable. The restricted distribution of populations of Emys infected with haemogregarines in Sicily is quite puzzling and the possible human-mediated introduction of the parasite in Sicily is briefly discussed.
\end{abstract}

Keywords: haemoprotozoans, blood parasitism, Italy, parasite spill-over, conservation.

Haemogregarines (Coccidia: Adeleorina) are the most widely distributed blood parasites in turtles worldwide (Adl et al. 2012). They have complex life cycles which involve merogony and the formation of gametocytes in a vertebrate host, and gamogony and sporogony in the gut of an invertebrate vector (Telford 2008). Although the sporozoites of these parasites live in invertebrate hosts, the merozoites are thought to be transmitted to turtles by leeches (Paperna 1989, Siddall and Desser 2001). Larger turtles are better targets for leech attachment because of their larger surface area (Readel et al. 2008). Haemogregarine species are common and widely distributed in freshwater turtles (Segade et al. 2006, Zelmer and Platt 2008, Dvořáková et al. 2014). Danilewsky (1885) reported the presence of the parasite in the European pond turtle Emys orbicularis (Linnaeus) and described it under the name Haemogregarina stepanowi Danilewsky, 1885.

The specificity of haemogregarines to the intermediate vertebrate hosts is quite low and the same taxon might, in fact, infect different turtle species (Siddall and Desser 2001, Dvořáková et al. 2014). Conversely, the distribution of haemogregarines seems to be determined by the distri- bution of their definitive host, usually a glossiphoniid leech of the genus Placobdella (Blanchard) (see Dvořáková et al. 2015).

Emys trinacris Fritz, Fattizzo, Guicking, Tripepi, Pennisi, Lenk, Joger et Wink is a Sicilian endemic pond turtle. Although it is morphologically similar to E. orbicularis sensu lato (s.1.) (see Fritz et al. 2006), molecular taxonomic studies have unambiguously revealed the presence of significant differences between the two species, which are adelphotaxa (Fritz et al. 2005, Pedall et al. 2011, Vamberger et al. 2015). In spite of the biogeographical and evolutionary importance of this chelonian species and the reduction of its populations caused by habitat destruction, pollution and pathogens, E. trinacris was listed in the IUCN Red List as 'Data Deficient' (van Dijk 2009), thus highlighting the need for further studies aimed at its characterising and monitoring of its health status.

In consideration of the recent finding of glossiphoniid leeches parasitising the Sicilian pond turtle (Marrone et al. 2016a), the possible occurrence of apicomplexan haemoparasites in the blood cells of wild populations of E. trinacris was investigated. 
Table 1. Geographical coordinates of the sampled sites and synopsis of the studied blood samples of Emys trinacris Fritz, Fattizzo, Guicking, Tripepi, Pennisi, Lenk, Joger et Wink.

\begin{tabular}{lcc}
\hline Sites & \multicolumn{1}{c}{ Coordinates } & Infected/examined \\
\hline Lago Urio Quattrocchi, Mistretta (ME) & $37^{\circ} 54^{\prime} 04^{\prime \prime} \mathrm{N} ; 14^{\circ} 23^{\prime} 46^{\prime \prime} \mathrm{E}$ & $3 / 4$ \\
Lago di Spartà, S. Agata di Militello (ME) & $38^{\circ} 01^{\prime} 50^{\prime \prime} \mathrm{N} ; 14^{\circ} 38^{\prime} 52^{\prime \prime} \mathrm{E}$ & $0 / 2$ \\
Laghetto Frattina, Corleone (PA) & $37^{\circ} 51^{\prime} 57^{\prime \prime} \mathrm{N} ; 13^{\circ} 18^{\prime} 14^{\prime \prime} \mathrm{E}$ & $0 / 13$ \\
Laghetto Coda di Riccio, Godrano (PA) & $37^{\circ} 52^{\prime} 23^{\prime \prime} \mathrm{N} ; 13^{\circ} 23^{\prime} 55^{\prime \prime} \mathrm{E}$ & $0 / 11$ \\
Laghetto presso Valle Maria, Godrano (PA) & $37^{\circ} 52^{\prime} 56^{\prime \prime} \mathrm{N} ; 13^{\circ} 24^{\prime} 40^{\prime \prime} \mathrm{E}$ & $0 / 4$ \\
Lago presso C/da Costa del Renoso, Monreale (PA) & $37^{\circ} 53^{\prime} 01^{\prime \prime} \mathrm{N} ; 13^{\circ} 02^{\prime} 35^{\prime \prime} \mathrm{E}$ & $0 / 7$ \\
Laghetto presso C/da Volta di Falce, Monreale (PA) & $37^{\circ} 52^{\prime} 01^{\prime \prime} \mathrm{N} ; 12^{\circ} 57^{\prime} 42^{\prime \prime} \mathrm{E}$ & $0 / 18$ \\
Lago Gorgo, Montallegro (AG) & $37^{\circ} 24^{\prime} 31^{\prime \prime} \mathrm{N} ; 13^{\circ} 19^{\prime} 27^{\prime \prime} \mathrm{E}$ & $0 / 30$ \\
Canale di Pantano Longarini, Ispica (RG) & $36^{\circ} 42^{\prime} 26^{\prime \prime} \mathrm{N} ; 15^{\circ} 00^{\prime} 32^{\prime \prime} \mathrm{E}$ & $0 / 4$ \\
Laghetti di Contrada Pantana, Caronia (ME) & $37^{\circ} 56^{\prime} 57^{\prime \prime} \mathrm{N} ; 14^{\circ} 33^{\prime} 05^{\prime \prime} \mathrm{E}$ & $6 / 6$ \\
Chiusa Arcera, Monreale (PA) & $37^{\circ} 54^{\prime} 58^{\prime \prime} \mathrm{N} ; 13^{\circ} 23^{\prime} 28^{\prime \prime} \mathrm{E}$ & $0 / 2$ \\
\hline
\end{tabular}

AG - province of Agrigento; ME - province of Messina; PA - province of Palermo; RG - province of Ragusa.

\section{MATERIALS AND METHODS}

Sampling. One hundred one sicilian pond turtles were sampled at eleven sites located on the Sicilian mainland (Table 1). To account for the possible ecological preferenda of all the components of this host-parasite system, sampling sites were included from different altitudes and different environmental landscapes selected, including both low-altitude water bodies and the highest localities of well-known occurrence for Emys trinacris (see Marrone et al. 2016b). Specimens of E. trinacris were captured by hands or by hoop net traps left overnight in concealed sites (Ream and Ream 1966). After clinical examination involving general inspection and detailed macroscopic inspection of the skin, plastron and carapace, blood samples were taken for cytological, haematological and molecular analyses. Blood samples were obtained from the dorsal coccygeal vessel of each collected turtle. After blood samples had been obtained, the animals were immediately released into their natural environments. For each individual, two blood smears and one blood sample in ethanol were collected.

Blood smears were prepared in situ according to Arizza et al. (2014). A blood drop was smeared on a glass slide and airdried. The sample was then fixed in methanol and stained according to the Pappenheim method (May-Grünwald + Giemsa-Romanowsky staining diluted $1: 10$ in buffered water, $\mathrm{pH}$ 7) for $20 \mathrm{~min}$, and washed in running tap water for 2 minutes. Stained blood smears were examined under a Leica DMRE light microscope using a $100 \times$ magnification oil immersion lens equipped with a digital camera (Leica DCF420 C, Leica, Wetzlar, Germany) (Fig. 1). Imaging software (Leica Application Suite, Leica) was used to examine the slides and perform calculations.

The intensity of infection was estimated by counting $10^{3}$ red blood cells (RBC) for each animal. For study of the erythrocyte shape, 60 erythrocytes for each slide were measured (15 uninfected, 15 infected with trophozoites, 15 infected with microgametocytes and 15 infected with macrogametocytes). Four parameters were considered: lengths (L) and widths (W) and nuclear lengths (NL) and nuclear widths (NW). Erythrocyte sizes (ES) and their nuclei sizes $(\mathrm{NS})$ were calculated as $\mathrm{ES}=(\mathrm{EL} \times \mathrm{EW} \times \pi) / 4$ and $\mathrm{NS}=(\mathrm{NL} \times \mathrm{NW} \times \pi) / 4$ (Arikan and Cicek, 2010). Cells and nuclear shapes were compared with the EL/EW and NL/NW ratios, and the nucleus/cytoplasm, with the NS/ES ratio.

The blood cell types were identified and counted according to Arizza et al. (2014). Haematological and parasite variables (num- ber or sizes) were summarised as the mean, standard deviation (SD), standard error of the mean (SE), and range.

Molecular evaluation. DNA extraction was carried out on two blood samples from infected E. trinacris specimens collected in Laghetti di Contrada Pantana and Lago Urio Quattrocchi with an innuPREP DNA mini kit (Analytik Jena, Jena, Germany) following the manufacturer's protocol. A partial sequence of the nuclear $18 \mathrm{~S}$ rRNA gene was amplified through the specific apicomplexan primers (EF: 5'-GAAACTGCGAATGGCTCATT-3' and ER: 5'-TTGCGCCTACTAGGCATTC-3') designed by Kvičerová et al. (2008). The target fragment is considered sufficiently variable and informative at both the generic and specific levels in Apicomplexa (Barta et al. 2012, Dvořáková et al. 2014, 2015, Özvegy et al. 2015).

The PCR mix consisted of $2 \mu$ of BIORON 10X ammonium buffer with $25 \mathrm{mM} \mathrm{MgCl}_{2}, 0.4 \mu \mathrm{l}$ of each dNTP at $10 \mathrm{mM}, 1 \mu \mathrm{l}$ of each $10 \mu \mathrm{M}$ primer, $0.2 \mu \mathrm{l}$ of BIORON DFS-Taq DNA Polymerase, $2 \mu \mathrm{l}$ of DNA template and $12.2 \mu \mathrm{l}$ of double-distilled water, for a total reaction volume of $20 \mu \mathrm{l}$.

The amplification consisted of an initial denaturation step of $95^{\circ} \mathrm{C}$ for $5 \mathrm{~min} ; 35$ cycles of $92^{\circ} \mathrm{C}$ for $45 \mathrm{~s}, 58^{\circ} \mathrm{C}$ for $45 \mathrm{~s}$ and $72{ }^{\circ} \mathrm{C}$ for $90 \mathrm{~s}$; and a final extension at $72{ }^{\circ} \mathrm{C}$ for $10 \mathrm{~min}$.

PCR products were checked on a $1 \%$ agarose gel, purified using the ExoSAP-IT enzymatic cleanup (USB Europe GmbH, Staufen, Germany) and sequenced in both directions on an ABI 3730xl Genetic Analyzer (Applied Biosystems, Foster City, CA, USA) using the BigDye Terminator v3.1 Cycle Sequencing Kit (Applied Biosystems). Chromatograms were imported and edited with Chromas Lite 2.01 (Technelysium Pty Ltd., South Brisbane, Australia). The sequences obtained from Lago Urio Quattrocchi and Laghetti presso Contrada Pantana were deposited in GenBank under accession numbers KX691417 to KX691418 respectively.

Eleven $18 \mathrm{~S}$ sequences belonging to different Haemogregarina species were downloaded from GenBank (see Fig. 2 for GenBank Accession Numbers); furthermore, a sequence belonging to Hemolivia mauritanica (Sergent et Sergent, 1904) was included in the analysis to be used as an outgroup.

Novel and GenBank sequences were aligned with BioEdit (Ibis Biosciences, Carlsbad, CA, USA) (Hall 1999), resulting in trimmed alignments of $1243 \mathrm{bp}$. A few insertions are present in the sequences of Hemolivia mauritanica (GenBank accession number: KF992710), Haemogregarina balli Paterson et Desser, 1976 (GenBank Accession number: HQ224959) and H. pel- 


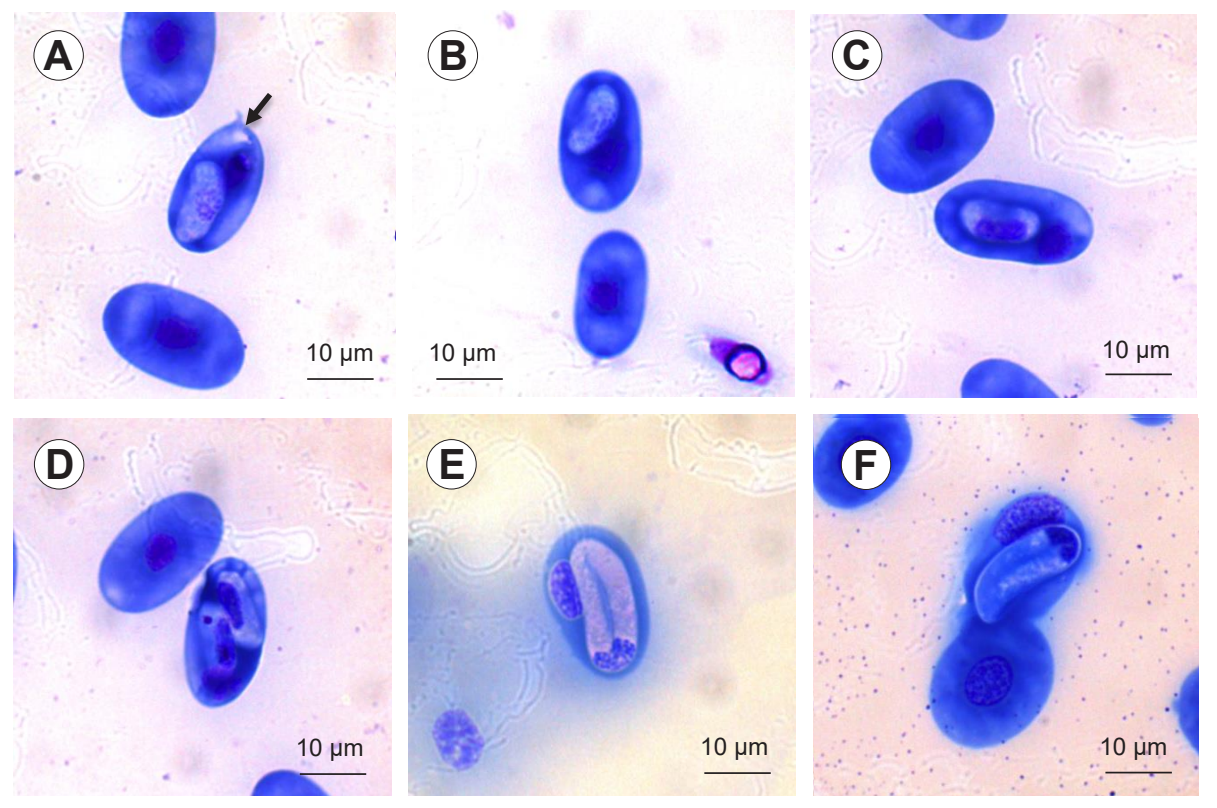

Fig. 1. Endogenous life stages of Haemogregarina stepanowi Danilewsky, 1885 from Emys trinacris Fritz, Fattizzo, Guicking, Tripepi, Pennisi, Lenk, Joger et Wink stained with May-Grünwald Giemsa-Romanowsky method. A-D - gametocytes at different stages of maturity, A, B - macrogametocyte with granular nucleus (in A arrow - vacuole); C, D-microgametocyte with a dense, homogeneous, central nucleus, note the erythrocyte which contains two microgametocytes in D; E, F - mature trophozoites are curved in a capsule with the nucleus located at the bend.

legrini (Laveran et Pettit, 1910) (GenBank a.n.: KM887509). Bayesian inference (BI) of the phylogeny and maximum-likelihood (ML) analyses were then performed as implemented in MrBayes 3.2.6 (Ronquist et al. 2012) and PhyML v.3 (Guindon et al. 2010). Both analyses were performed using a generalised time reversible model of sequence evolution with a proportion of invariable sites $(\mathrm{GTR}+\mathrm{I})$, as selected by the Akaike information criterion in jModelTest 2.1.9 (Darriba et al. 2012). Node supports were evaluated by their posterior probabilities in the BI tree and with 1000 bootstrap replicates in the ML analysis.

The BI analysis was performed with two independent runs of 2000000 generations and four Markov chains using default heating values. Trees and parameter values were sampled every 100 generations, resulting in 20000 saved trees per analysis. An initial fraction of 5000 trees $(25 \%)$ was conservatively discarded as 'burn-in'. In the BI analysis, the standard deviation of the split frequencies reached values lower than 0.011 , and values of the potential scale reduction factor were 1.000 for all parameters, indicating convergence of the runs.

Ethics. Specimens of Emys trinacris were sampled and examined according to the national laws and considering all ethical requirements. The investigation was carried out with permission of the Ministero dell'Ambiente e della Tutela del Territorio e del Mareof the Republic of Italy under permission code U. prot. PNM-2011-0022035 25/10/2011 and PNM-2014-0008884.

\section{RESULTS}

\section{Blood smear analysis}

Based on the microscopic study of blood smear samples, only nine specimens out of the 101 turtles examined were positive for haemogregarines (Table 1). Six of these specimens were collected in Laghetti di Contrada Pantana and three specimens in Lago Urio Quattrocchi, both located in the Nebrodi mountain range. This represents the first report of haemogregarines in free-ranging aquatic turtles from Italy, specifically from Sicily. In the two infected populations, $75-100 \%$ of the studied specimens of E. trinacris proved to be infected with haemogregarines. Conversely, no evidence for the presence of haemogregarine parasites was observed in the 92 Sicilian pond turtles collected at the other nine sampling sites, all of them located outside of the Nebrodi mountain range. Accordingly, the observed overall percentage of mean prevalence in Sicily stood at approximately $9 \%$ at the regional level.

\section{Morphology of haemogregarine parasites and infected erythrocytes}

In the examined infected specimens, we most frequently observed three developmental stages located inside the red cells of the peripheral blood as reported for haemogregarines in turtle hosts by Telford (2008): microgametocyte, macrogametocyte and trophozoite (Fig. 1). Parasites of Sicilian pond turtles were morphologically similar and consistently adjacent to the nuclei of the host cells.

Macrogametes, each with an oval shape and a granular nucleus, were usually located near the erythrocyte nucleus (Fig. 1A,B) and measured on average $12.9 \pm 0.6 \mu \mathrm{m}$ in length and $6.0 \pm 0.6 \mu \mathrm{m}$ in width. The microgametes had a bean shape and a large central nucleus (Fig. 1C,D). Their sizes were $13.2 \pm 0.1 \mu \mathrm{m}$ in length and $6.4 \pm 0.5 \mu \mathrm{m}$ in width. The nucleus size was $8.6 \pm 1.0 \mu \mathrm{m}$ in length and $3.7 \pm 0.6 \mu \mathrm{m}$ in width. The mature trophozoites were U-shaped, with arms of unequal size partially fused, forming a large oval body contained in a capsule and appearing withdrawn into themselves, with the nucleus posi- 
Table 2. Dimensions from uninfected erythrocytes (U) of Emys trinacris Fritz, Fattizzo, Guicking, Tripepi, Pennisi, Lenk, Joger et Wink compared with erythrocytes infected with microgranulocyte $(M)$ and trophozoite (T).

\begin{tabular}{lccccccccc}
\hline Turtle & $\mathrm{EL}$ & $\mathrm{EW}$ & $\mathrm{L} / \mathrm{W}$ & $\mathrm{ES}\left(\mu \mathrm{m}^{2}\right)$ & $\mathrm{NL}$ & $\mathrm{NW}$ & $\mathrm{NL} / \mathrm{NW}$ & $\mathrm{NS}\left(\mu \mathrm{m}^{2}\right)$ & $\mathrm{NS} / \mathrm{ES}$ \\
\hline $\mathrm{U}$ & $22.2 \pm 1.34$ & $12.6 \pm 0.7$ & $1.6 \pm 0.05$ & $214.2 \pm 14.57$ & $6.58 \pm 1.49$ & $5.3 \pm 0.22$ & $1.2 \pm 0.22$ & $27.9 \pm 7.55$ & $0.12 \pm 0.03$ \\
$\mathrm{M}$ & $23.6 \pm 0.93$ & $13.9 \pm 0.91^{*}$ & $1.7 \pm 0.18$ & $258.5 \pm 21.49^{*}$ & $6.44 \pm 1.05$ & $5.6 \pm 0.93$ & $1.1 \pm 0.16$ & $29.2 \pm 8.44$ & $0.11 \pm 0.03$ \\
$\mathrm{~T}$ & $25.5 \pm 0.73^{* *}$ & $15.7 \pm 0.50^{* *}$ & $1.62 \pm 0.5^{*}$ & $317.1 \pm 19.27^{* *} 10.39 \pm 0.16^{* *}$ & $4.7 \pm 0.09^{* *}$ & $2.1 \pm 0.01^{* *}$ & $38.4 \pm 3.48^{*}$ & $0.12 \pm 0.01$ \\
\hline
\end{tabular}

All the record are $\mu \mathrm{m} \pm \mathrm{SD}$; EL - erythrocyte length; EW - erythrocyte width; L/W - ratio; ES - erythrocyte size; NL - nucleus length; NW - nucleus width; NS - nucleus size; ES and NS were calculated with the respective formulas (see the text).

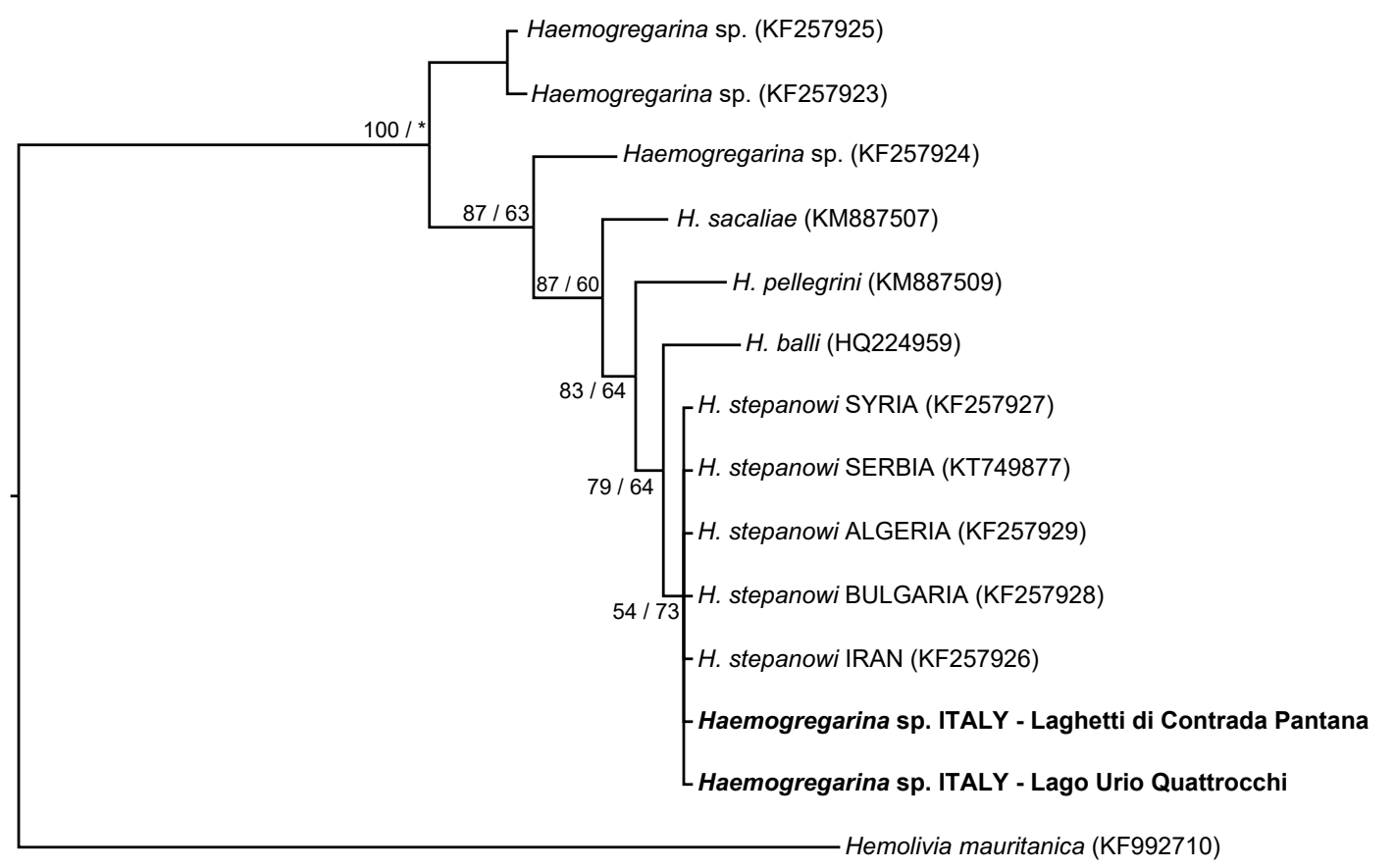

Fig. 2. Bayesian phylogram based on a fragment of the nuclear 18S rRNA. Node support is reported as nodal posterior probabilities/ ML bootstrap, expressed in percentages; values below 50 are indicated with an asterisk. The accession numbers of sequences derived from GenBank are shown in parentheses.

tioned on the bend (Fig. 1E,F). The trophozoite measured $21.6 \pm 1.5 \mu \mathrm{m}$ in length and $7.9 \pm 0.9 \mu \mathrm{m}$ in width.

The predominant stages in our samples were macrogametocytes (97\%), whereas microgametocytes and trophozoites were rarely observed ( $2 \%$ and $1 \%$, respectively).

Infected erythrocytes had a normal or elongated shape compared to that of control erythrocytes (see Table 2 for measurements). The nucleus was displaced to a marginal position (Fig. 1E,F) or to a polar position (Fig. 1A,C). In some cases, a vacuole was observed near the trophozoite (Fig. 1A). Shape alteration was observed in erythrocytes infected with microgametocytes with expansions (Fig. 1D), or with rarely occurring double infections.

\section{Molecular identification}

Sequencing of the $18 \mathrm{~S}$ rRNA fragment confirmed the presence of Haemogregarina sp. in the blood of the Sicilian pond turtles. The topologies of the phylogenetic trees based on BI and ML analyses were largely congruent and allowed the identification of the Haemogregarina species occurring in the Sicilian pond turtle as H. stepanowi, which exhibits a close sister-taxon relation with the Nearctic Haemogregarina balli (Fig. 2).

\section{DISCUSSION}

We report for the first time the presence of haemogregarines in the erythrocytes of the endemic Sicilian pond turtle Emys trinacris. Based on the morphology of the intra-erythrocytic stages, according to Mihalca et al. (2002), we were able to identify the observed haemogregarine species as Haemogregarina stepanowi; this identification was also confirmed by the sequencing of a fragment of the nuclear $18 \mathrm{~S}$ rRNA gene. $H$. stepanowi is a widespread species in the Palaearctic region, ranging from Croatia to Iran and the Middle East (Mishra and González 1978, Reichenow 1910, Mihalca et al. 2008, Dvořáková et al. 2014, Javanbakht and Sharifi 2014 and references therein), where it is able to infect freshwater turtles belonging to the families of Emydidae and Geoemydidae. Until now H. stepanowi has not reported from Italy, nor, to the best of our knowledge, is any record of the presence of this apicomplexan parasite available for European countries west of $13^{\circ} \mathrm{E}$. In our opinion, such an apparent absence is most likely to be ascribed to the lack of dedicated surveys rather than to the actual absence of this intracellular parasite in western Europe. The intermediate (i.e. species of Mauremys [Gray] and Emys [Duméril] taxa) and definitive (i.e. the leech, Placobdella 
costata [Müller]) hosts of the species are, in fact, known to widely occur in western Europe.

The infection with $H$. stepanowi induces different changes in the erythrocyte shape, depending on the infective stage. The more marked changes occur in the case of infection with trophozoites because of their large size and elongated shape; infected erythrocytes are longer and slightly narrower with a significantly higher $\mathrm{L} / \mathrm{W}$ ratio and with an erythrocyte surface (ES) significantly larger compared to the uninfected erythrocytes $(\mathrm{N})$. The length of the nucleus is also significantly increased, but its width is reduced, giving a flattened aspect to the nucleus with a significantly higher $\mathrm{L} / \mathrm{W}$ ratio.

In erythrocytes infected with microgametocytes, the changes are less evident. The cells are slightly bigger, with a nucleus confined to a cell pole or adhering to the membrane. Normal morphometric values of erythrocytes in E. trinacris were studied by Arizza et al. (2014). In the present study, all morphometric values for the infected erythrocytes were within the ranges reported by Arizza et al. (2014) except EW and ES, which were slightly smaller than in the uninfected turtles.

The differential count of the leukocytes of specimens parasitised with $H$. stepanowi compared to data of Arizza et al. (2014) on healthy specimens, are not significantly different.

The consequences of a parasitosis by haemogregarines on the number of blood cells is not yet clear, but an intense parasitism by haemogregarines has been reported to increase the number of lymphocytes and decrease the number of eosinophils in freshwater turtles (Mihalca et al. 2002). Conversely, Salakij et al. (2002) did not find significant differences in the differential blood cell counts in puff-faced water snakes, Homalopsis buccata (Linnaeus) parasitised with Haemogregarina sp.

Haemogregarine blood parasites are generally considered to have little obvious effect on aquatic turtles, but some evidence of an impact of $H$. stepanowi on the occurrence of shell necrosis and skin haemorrhages in Serbian Emys orbicularis has been collected (Özvegy et al. 2015). Therefore, careful monitoring of the health status of infected populations is advisable.

The nine infected Sicilian pond turtles we examined appeared otherwise healthy, and the level of observed haemogregarine infection was generally low: less than $1 \%$ of the erythrocytes contained parasites in most turtles. In con- trast, a local parasitemia of $75-100 \%$ was present in the only two Sicilian sites where $H$. stepanowi was observed (see Table 1).

In good accordance with the known specificity of Haemogregarina spp. with their definitive hosts, the Nebrodi mountain range is the only area in Sicily where the definitive host of $H$. stepanowi, i.e. the leech $P$. costata, is known to occur. Interestingly, specimens of $P$. costata from Sicily are genetically identical to those occurring in southern Italy, which is in contrast to the sharp genetic differentiation between their vertebrate hosts, i.e. the Sicilian E. trinacris and the Italian E. orbicularis s.l. (see Marrone et al. 2016a). Such an unexpected decoupling might be due to a recent, human-mediated introduction of the leech to Sicily, which would be also supported by the evidence of the presence of introduced specimens of E. orbicularis from Italy in Lago Urio Quattrocchi (Vamberger et al. 2015), or to a natural long-range passive dispersal event of the species, which is reported to be able to be dispersed by non-chelonian vertebrates with aquatic afinity (Vamberger and Trontelj 2007, Bielecki et al. 2012, Marrone et al. 2016a).

If the introduced European pond turtles functioned as vectors for the passive dispersal of $P$. costata and $H$. stepanowi in Sicily, the presence of $H$. stepanowi in the Sicilian pond turtle should be considered a case of "parasite spill-over', a phenomenon already known to affect European freshwater turtles (e.g. Iglesias et al. 2015). The genetic characterisation of Sicilian and Italian populations of $H$. stepanowi, possibly implementing fast-evolving molecular markers, would allow testing for the existence in Sicily of autochthonous vs introduced strains of $H$. stepanowi, and for the development of adequate management plans.

On the basis of this information and considering the possible anthropogenic introduction of $H$. stepanowi to Sicily, the health status and the population dynamics of infected populations of E. trinacris should be carefully monitored to check for possible detrimental long-term effects of this haemoparasite on the conservation of the endemic Sicilian pond turtle.

Acknowledgements. The Italian Ministero dell'Ambiente e della Tutela del Territorio e del Mare is gratefully acknowledged for having provided the permit to allow sampling of Emys spp. in Sicily and southern Italy (PNM-2011-0022035, PNM-2014-0008884). Two anonymous reviewers are acknowledged for their constructive criticism, which allowed us to improve the manuscript.

\section{REFERENCES}

Adl S.M., Simpson A.G.B., Lane C.E., Lukeš J., Bass D., Bowser S.S., Brown M.W., Burki F., Dunthorn M., Hampl V., Heiss A., Hoppenrath M., Lara E., Le Gall L., Lynn D.H., McManus H., Mitchell E.A.D., Mozley-Stanridge S.E., Parfrey L.W., Pawlowski J., Rueckert S., Shadwick L., Schoch C.L., Smirnov A., Spiegel F.W. 2012: The revised classification of eukaryotes. J. Eukaryot. Microbiol. 59: 429-514.

Arikan H., CiCEK K. 2010: Morphology of peripheral blood cells from various species of Turkish herpetofauna. Acta Herpetol. 5: 179-198.
Arizza V., Russo D., Marrone F., Sacco F., Arculeo M. 2014: Morphological characterization of the blood cells in the endangered Sicilian endemic pond turtle, Emys trinacris (Testudines: Emydidae). Ital. J. Zool. 81: 344-353.

Barta J.R., Ogedengbe J.D., Martin D.S., Smith T.G. 2012: Phylogenetic position of the adeleorinid coccidia (Myzozoa, Apicomplexa, Coccidia, Eucoccidiorida, Adeleorina) inferred using 18S rDNA sequences. J. Eukaryot. Microbiol. 59: 171-180.

Bielecki A., Cichocka J.M., Jabloński A., Jeleń I., Ropelewska E., Biedunkiewicz A., Terlecki J., Nowakowski J.J., Pakulnicka J., Szlachciak J. 2012: Coexistence of Pla- 
cobdella costata (Fr. Müller, 1846) (Hirudinida: Glossiphoniidae) and mud turtle Emys orbicularis. Biologia 67: 731-738.

Danilewsky B. 1885: Die Hämatozoën der Kaltblüter. Archiv Mikrosk. Anatomie 24: 588-598.

Darriba D., Taboada G.L., Doallo R., Posada D. 2012: jModelTest 2: more models, new heuristics and parallel computing. Nat. Methods 9: 772.

VAN DiJK P.P. 2009: Emys trinacris. The IUCN Red List of Threatened Species 2009: e.T158469A5199795.

Dvořáková N., KviČErová J., Hostovský M., ŠırokÝ P. 2015: Haemogregarines of freshwater turtles from Southeast Asia with a description of Haemogregarina sacaliae sp. n. and a redescription of Haemogregarina pellegrini Laveran and Pettit, 1910. Parasitology 142: 816-826.

Dvořáková N., Kvičerová J., Papoušek I., Javanbakht H., Tiar G., Kami H., ŠIrokÝ P. 2014: Haemogregarines from western Palaearctic freshwater turtles (genera Emys, Mauremys) are conspecific with Haemogregarina stepanowi Danilewsky, 1885. Parasitology 141: 522-530.

Fritz U., D’Angelo S., Pennisi M.G., Lo Valvo M. 2006: Variation of Sicilian pond turtles, Emys trinacris - what makes a species cryptic? Amphibia-Reptilia 27: 513-529.

Fritz U., Fattizzo T., Guicking D., Tripepi S., Pennisi M.G., Lenk P., Joger U., Wink M. 2005: A new cryptic species of pond turtle from southern Italy, the hottest spot in the range of the genus Emys (Reptilia, Testudines, Emydidae). Zool. Scr. 34: 351-371.

Guindon S., Dafayard J.F., Lefort V., Anisimova M., HordiJK W., Gascuel O. 2010: New algorithms and methods to estimate maximum-likelihood phylogenies: assessing the performance of PhyML 3.0. Syst. Biol. 59: 307-321.

HaLl T.A. 1999: BioEdit: a user-friendly biological sequence alignment editor and analysis program for Windows 95/98/NT Nucl. Acids Symp. Ser. 41: 95-98.

Iglesias R., Garcia-Estevez J.M., Ayres C., Acuna A., Cordero-Rivera. A. 2015: First reported outbreak of severe spirorchiidiasis in Emys orbicularis, probably resulting from a parasite spillover event. Dis. Aquat. Organ. 113: 75-80.

Javanbaknt H., Sharifi M. 2014: Prevalence and intensity of Haemogregarina stepanowi (Apicomplexa: Haemogregarinidae) in two species of freshwater turtles (Mauremys caspica and Emys orbicularis) in Iran. J. Entomol. Zool. Stud. 2: 155-158.

Kvičerová J., Pakandl M., Hypša V. 2008: Phylogenetic relationships among Eimeria spp. (Apicomplexa, Eimeriidae) infecting rabbits: evolutionary significance of biological and morphological features. Parasitology 135: 443-452.

Marrone F., Sacco F., Arizza V., Arculeo M. 2016b: Amendment of the type locality of the endemic Sicilian pond turtle Emys trinacris Fritz et al. 2005, with some notes on the highest altitude reached by the species (Testudines, Emydidae). Acta Herpetol. 11: 59-61.

Marrone F., Sacco F., Kehlmaier C., Arizza V., ArcuLEO M. 2016a: Some like it cold: the glossiphoniid parasites of the Sicilian endemic pond turtle Emys trinacris (Testudines, Emydidae), an example of 'parasite inertia'? J. Zool. Syst. Evol. Res. 54: 60-66.

Mihalca A., Achelăriței D., Popescu P. 2002: Haemoparasites of the genus Haemogregarina in a population of European pond turtles (Emys orbicularis) from Drăgăşani, Vâlcea county, Romania. Sci. Parasitol. 3: 22-27.

Minalca A., RaČKa K., Gherman C., Ionescu D. 2008: Prevalence and intensity of blood apicomplexan infections in reptiles from Romania. Parasitol. Res. 102: 1081-1083.
Mishra G., GonZÁlez J. 1978: Parasites of fresh water turtles in Tunisia. Arch. Institut Pasteur 55: 303-326.

Özvegy J., Marinković D., Vučićević M., Gajić B., Stefanović J., Krnjaić D., Aleksić-Kovačević S., 2015: Cytological and molecular identification of Haemogregarina stepanowi in blood samples of the European pond turtle (Emys orbicularis) from quarantine at Belgrade zoo. Acta Veterinaria-Beograd 65: 443-453.

Paperna I. 1989: Developmental cycle of chelonian haemogregarines in leeches with extra-intestinal multisporozoite ocysts and a note on the blood stages in the chelonian hosts. Diseases of Aquatic Organisms 7: 149-153.

Pedall I., Fritz U., Stuckas H., Valdeon A., Wink M. 2011: Gene flow across secondary contact zones of the Emys orbicularis complex in the Western Mediterranean and evidence for extinction and re-introduction of pond turtles on Corsica and Sardinia (Testudines: Emydidae). J. Zool. Syst. Evol. Res. 49: 44-57.

Readel A.M., Phillips C.A., Wetzel M.J. 2008: Leech parasitism in a turtle assemblage: effects of host and environmental characteristics. Copeia 1: 227-233.

Ream C., Ream R. 1966: The influence of sampling methods on the estimation of population structure in painted turtles. Am. Midl. Nat. 75: $325-338$.

Reichenow E. 1910: Haemogregarina stepanowi. Die Entwicklungsgeschichte einer Hämogregarine. Arch. Protistenkd. 20: 325-338.

Ronquist F., Teslenko M.P., van der Mark D.L., Ayres A., Darling S., Höhna B., Larget L., Suchard M.A., HuelsenbeCK J.P. 2012: MrBayes 3.2: efficient Bayesian phylogenetic inference and model choice across a large model space. Syst. Biol. 61: 539-542.

Salakij C., Salakij J., Suthunmapinunta P., Chanhome L. 2002: Hematology, morphology and ultrastructure of blood cells and blood parasites from puff-faced watersnakes (Homalopsis buccata). Kasetsart J. (Nat. Sci.) 36: 35-43.

Segade P., Crespo C., Ayres C., Cordero A., Arias M.C., Garcia-Estevez J.M., Iglesias Blanco R. 2006: Eimeria species from the European pond turtle, Emys orbicularis (Reptilia: Testudines), in Galicia (NW Spain), with description of two new species. J. Parasitol. 92: 69-72.

Siddall M.E., Desser S.S. 2001: Transmission of Haemogregarina balli from painted turtles to snapping turtles through the leech Placobdella ornata J. Parasitol. 87: 1217-1218.

Stuckas H., Velo-Antón G., Fahd S., Kalboussi M., Rouag R., Arculeo M., Marrone F., Sacco F., Vamberger M., Fritz U. 2014: Where are you from, stranger? The enigmatic biogeography of North African pond turtles (Emys orbicularis). Org. Divers. Evol. 14: 295-306.

Telford JR. S.R. 2008: Hemoparasites of the Reptilia: Color Atlas and Text. CRC Press, New York, 376 pp.

Vamberger M., Stuckas H., Sacco F., D’Angelo S., Arculeo M., Cheylan M., Corti C., Marrone F., Wink M., Fritz U. 2015: Differences in gene flow in a twofold secondary contact zone of pond turtles in southern Italy (Testudines: Emydidae: Emys orbicularis galloitalica, E. o. hellenica, E. trinacris). Zool. Scr. 44: 233-249.

Vamberger M., Trontelu P. 2007: Placobdella costata (Fr. Müller, 1846) (Hirudinea: Glossiphoniidae), a leech species new for Slovenia. Natura Sloveniae 9: 37-42.

Zelmer D.A., Platt T.R. 2008: Structure and similarity of helminth communities of six species of Australian turtles. J. Parasitol. 94: 781-787.

Cite this article as: Arizza V., Sacco F., Russo D., Scardino R., Arculeo M., Vamberger M., Marrone F. 2016: The good, the bad and the ugly: Emys trinacris, Placobdella costata and Haemogregarina stepanowi in Sicily (Testudines, Annelida and Apicomplexa). Folia Parasitol. 63: 029. 